\title{
The incidence of congenital hypothyroidism (CH) in Guangxi, China and the predictors of permanent and transient $\mathbf{C H}$
}

\author{
Chunyun Fu' ${ }^{1,2,3, *}$, Shiyu Luo ${ }^{1, *}$, Yingfeng $\mathrm{Li}^{2,3, *}$, Qifei $\mathrm{Li}^{1}$, Xuehua $\mathrm{Hu}^{2}$, Mengting Li' ${ }^{1}$, \\ Yue Zhang', Jiasun Su', Xuyun Hu', Yun Chen'1, Jin Wang', Bobo Xie', Jingsi Luo', \\ Xin Fan', Shaoke Chen ${ }^{1}$ and Yiping Shen ${ }^{1,4}$
}

1'Department of Genetic Metabolism, Children's Hospital, Maternal and Child Health Hospital of Guangxi Zhuang Autonomous Region, Nanning, People's Republic of China

${ }^{2}$ Medical Science Laboratory, Children's Hospital, Maternal and Child Health Hospital of Guangxi Zhuang Autonomous Region, Nanning, People's Republic of China

${ }^{3}$ Department of pathology, Children's Hospital, Maternal and Child Health Hospital of Guangxi Zhuang Autonomous Region, Nanning, People's Republic of China

${ }^{4}$ Boston Children's Hospital, Harvard Medical School, Boston, Massachusetts, USA

*(C Fu, S Luo and Y Li contributed equally to this work)

\begin{abstract}
Background: The incidence of congenital hypothyroidism $(\mathrm{CH})$ differs significantly among different ethnicities and regions, and early differentiation of transient $\mathrm{CH}$ is important to avoid unnecessary prolonged treatment with $\mathrm{L}-\mathrm{T}_{4}$.

Objective: To investigate the incidence of $\mathrm{CH}$ based on the newborn screening program in Guangxi Zhuang Autonomous Region, China, and to analyze the predictors that might allow for an early differentiation between permanent $(\mathrm{P})$ and transient $(\mathrm{T}) \mathrm{CH}$. Design and methods: Data from newborn screening program over a seven-year period (January 2009 to January 2016) at Guangxi Maternal and Child Health Hospital are analyzed. Blood samples were collected on filter paper between 3 and 7 days after birth, and TSH level was measured by time-resolved fluorescence assay. Individuals with increased TSH (TSH $\geq 8 \mathrm{IU} / \mathrm{L}$ ) levels detected by newborn screening were recalled for further evaluation. Serum $\mathrm{TSH}, \mathrm{FT}_{3}$ and $\mathrm{FT}_{4}$ were determined by electrochemiluminescence assay using venous blood samples. Diagnosis of $\mathrm{CH}$ is based on elevated TSH levels ( $>10 \mathrm{IU} / \mathrm{L}$ ) and decreased $\mathrm{FT}_{4}$ levels $(<12 \mathrm{pmol} / \mathrm{L})$. Patients with elevated $\mathrm{TSH}$ levels and normal $\mathrm{FT}_{4}$ levels were diagnosed as hyperthyrotropinemia. Permanent or transient $\mathrm{CH}$ was determined by using the results of thyroid function tests after temporary withdrawal of L- $\mathrm{T}_{4}$ therapy at approximately $2-3$ years of age. Results: Among 1,238,340 infants in the newborn screening program, 14,443 individuals were recalled for reevaluation (re-call rate 1.18\%), 911 and 731 individuals were subsequently determined to have hyperthyrotropinemia and $\mathrm{CH}$ respectively; thus, a prevalence of 1:1359 and 1:1694 for hyperthyrotropinemia and $\mathrm{CH}$. Of the 731 patients with $\mathrm{CH}, 161$ patients were diagnosed with permanent $\mathrm{CH}(\mathrm{PCH})$, and 159 patients were diagnosed with transient $\mathrm{CH}(\mathrm{TCH})$, the other 411 patients are too young to determine their subtypes. Patients with $\mathrm{PCH}$ required an increasing dose of $\mathrm{L}_{-} \mathrm{T}_{4}$ during the first few years, whereas patients with TCH required a decreased dose of $L-T_{4}$. The TSH levels at diagnosis and the dose of $\mathrm{L}-\mathrm{T}_{4}$ used were significantly higher in $\mathrm{PCH}$ cases than in
\end{abstract}

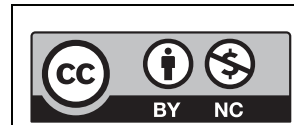

This work is licensed under a Creative Commons Attribution-NonCommercial 4.0 International License.

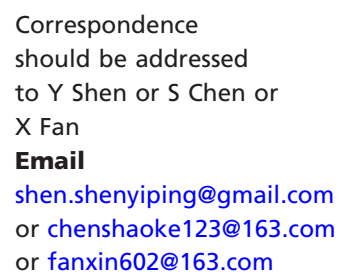

http://www.endocrineconnections.org DOI: 10.1530/EC-17-0289 (c) 2017 The authors Published by Bioscientifica Ltd
Key Words

- congenital hypothyroidism

- prevalence

- predictor

- L-T ${ }_{4}$ dose

- Guangxi

- China 
transient cases. The $\mathrm{FT}_{4}$ levels at diagnosis were significantly lower in $\mathrm{PCH}$ cases than in $\mathrm{TCH}$ cases. The TSH levels at diagnosis, $\mathrm{FT}_{4}$ levels at diagnosis and $\mathrm{L}-\mathrm{T}_{4}$ doses at 90 days were evaluated as predictors for differentiating $\mathrm{PCH}$ and $\mathrm{TCH}$, and their accuracy at their respective optimal cutoffs were determined to be $60.6 \%, 66.7 \%$ and $93.9 \%$, respectively. Conclusions: The $\mathrm{CH}$ incidence in Guangxi Zhuang Autonomous Region is slightly higher (1:1694) compared to the worldwide levels (1/2000-1/4000). The PCH and TCH ratio is close to 1 ; thus, the estimated PCH incidence is $1 / 3388$, which is similar to reported worldwide average incidence (1/3000). The $L-T_{4}$ dose required at 90 days ( $>30 \mu \mathrm{g} / \mathrm{day}$ ) has the highest predictive value for $\mathrm{PCH}$. Earlier differentiation of $\mathrm{PCH}$ and $\mathrm{TCH}$ helps to determine appropriate treatment course.

Endocrine Connections (2017) 6, 926-934

\section{Introduction}

Congenital hypothyroidism $(\mathrm{CH})$ is one of the most common causes of intellectual disability and growth retardation with worldwide incidence ranging from $1: 2000$ to $1: 4000$ newborns $(1,2,3)$. Newborn screening allows for early detection and treatment of $\mathrm{CH}$, thus effectively preventing intellectual disability and short stature due to lack of thyroid hormone.

The incidence of $\mathrm{CH}$ differs significantly among different ethnicities and regions. For example, Zeinalzadeh and coworkers reported a $\mathrm{CH}$ prevalence of 1:666 (TSH cutoff level 10IU/L) in East Azerbaijan, Iran (4), whereas a $\mathrm{CH}$ prevalence of 1:2591 (TSH cutoff level 10IU/L) was reported in the Republic of Macedonia (5). Two previous studies reported the $\mathrm{CH}$ prevalence based on newborn screening programs in Han Chinese, and the incidence of $\mathrm{CH}$ was reported as 1:1678 (TSH cutoff level 9IU/L) and 1:3009 (TSH cutoff level 10-15IU/L), respectively in Zhejiang (6) and Shanghai (7) province. Little is known about the incidence of $\mathrm{CH}$ in Guangxi Zhuang Autonomous Region, which is located in South-west China with a population of distinct ethnic composition.

$\mathrm{CH}$ can be classified into $\mathrm{PCH}$ and $\mathrm{TCH}$ according to the clinical course. PCH refers to a persistent deficiency of thyroid hormone that requires lifelong treatment. TCH refers to a temporary deficiency of thyroid hormone at the early stage of life, but thyroid hormone production recovers to normal afterwards. Recovery to euthyroidism typically occurs in the first few months or years of life. The current guidelines recommend that all $\mathrm{CH}$ children be re-evaluated at the age of 3 years (8). Early differentiation of $\mathrm{TCH}$ is important to avoid unnecessary prolonged treatment with $\mathrm{L}_{-} \mathrm{T}_{4}$, and it is also helpful for predicting prognosis and alleviating families' psychological burden. Thus, we investigated the $\mathrm{CH}$ incidence based on the newborn screening program in Guangxi Zhuang Autonomous Region, China and to analyze the factors that might allow an early differentiation between TCH and $\mathrm{PCH}$.

\section{Subjects and methods}

$1,238,340$ newborns were screened for $\mathrm{CH}$ at the duration from January 2009 to January 2016 at the Newborn Screening Center of Guangxi, China. This center is responsible for half of the total population in Guangxi province. The coverage for newborn screening is $95.2 \%$ for this part of the country. The screening follows a standard screening protocol. Between 3 and 7 days after birth, 3 drops of heel blood were collected on a filter paper (S\&S 903). The thyroid-stimulating hormone (TSH) level was measured by time-resolved fluorescence assay (Perkin Elmer).

The analytical sensitivity of TSH test was typically better than $0.002 \mathrm{IU} / \mathrm{L}$. The accuracy of the TSH test was assessed using both intra- and inter-assay. Intra-assay coefficients of variation at TSH concentrations of 14.6, 24.0 and $58.6 \mathrm{IU} / \mathrm{L}$ were $7.1,6.3$ and $7.0 \%$, respectively, while the inter-assay coefficients of variation at the same TSH concentrations were $8.1,9.0$ and $7.8 \%$, respectively. Subjects with increased $\mathrm{TSH}(\mathrm{TSH} \geq 8 \mathrm{IU} / \mathrm{L})$ levels were contacted and re-evaluated. Pre-term ( $<37$ weeks gestation) and low-birth-weight infants $(<2000 \mathrm{~g})$ underwent a second mass screening one month after birth, when their body weight reaches $2500 \mathrm{~g}$, even if data in the first screening at age 3-7 days was within the normal range.

The confirmatory test was carried out between 7 and 28 days after birth by electrochemiluminescence 
assay (Cobas e601, Roche Diagnostics) with venous blood samples. The test results were compared to agespecific reference as included in Supplementary Table 1 (see section on supplementary data given at the end of this article). Diagnosis of $\mathrm{CH}$ is based on elevated TSH levels $(>10 \mathrm{IU} / \mathrm{L})$ and decreased $\mathrm{FT}_{4}$ levels $(<12 \mathrm{pmol} / \mathrm{L})$. Patients with elevated TSH levels and normal $\mathrm{FT}_{4}$ levels were diagnosed as hyperthyrotropinemia (HT). Thyroid ultrasonography and ${ }^{99} \mathrm{mTc}$ scintigraphy were performed during the neonatal period before treatment. $\mathrm{L}_{-} \mathrm{T}_{4}$ replacement therapy started after the diagnosis of $\mathrm{CH}$, and the dose was adjusted according to the serum $\mathrm{TSH}$ and $\mathrm{FT}_{4}$ levels. The target serum $\mathrm{FT}_{4}$ level should be $>50 \%$ of the normal range by age. The target for TSH level should be within the normal range by age. Permanent $\mathrm{CH}$ was determined by temporary withdrawal of $\mathrm{L}-\mathrm{T}_{4}$ therapy at approximately 2-3 years of age. After one month of discontinuation of $\mathrm{L}_{-} \mathrm{T}_{4}$ treatment, TSH and $\mathrm{FT}_{4}$ levels were measured in venous blood sample. Individuals who showed contiguous dependency on L- $\mathrm{T}_{4}$ were diagnosed with permanent $\mathrm{CH}$. These children were then repeatedly evaluated at regular intervals for 1-1.5 years to monitor thyroid function. Those who did not need contiguous ${\mathrm{L}-\mathrm{T}_{4}}_{4}$ therapy were diagnosed with transient $\mathrm{CH}$. The study was approved by the Medical Ethics Committee of Guangxi Maternal and Child Health Hospital. Informed consent was obtained from the parents of the patients.
Table 1 Distribution of serum TSH levels among screened newborns $(n=12,38,340)$.

\begin{tabular}{|c|c|c|}
\hline Distribution of TSH levels (IU/L) & $\boldsymbol{N}$ & $\%$ \\
\hline $0-4.9$ & $11,40,493$ & 92.1 \\
\hline $5-7.9$ & 81,062 & 6.5 \\
\hline $8-9.9$ & 9805 & 0.8 \\
\hline $10-19.9$ & 6109 & 0.5 \\
\hline$\geq 20$ & 871 & 0.1 \\
\hline Total & $12,38,340$ & 100 \\
\hline
\end{tabular}

\section{Statistical analysis}

The data were analyzed using $\mathrm{R}$ software. Qualitative variables were compared using the Fisher test and quantitative variables were compared by $t$-test. All $P$ values were two-sided with $P<0.05$ being considered as significant. A receiver-operating characteristic (ROC) curve analysis was performed to identify the optimal cutoff values of predictor, which were able to distinguish between $\mathrm{PCH}$ and $\mathrm{TCH}$. The best cutoffs were defined by the highest Youden index ((specificity+sensitivity)-1).

\section{Results}

During the study period, 1,238,340 newborns were screened. A skewed gender ratio was noticed in this population: 667,676 (53.9\%) were male and 570,664 (46.1\%) were female. The female:male ratio was 1:1.17. $80 \%$ of samples were taken from neonates at 3-5 days

The TSH levels and positive rate in relation to the timing of blood sampling

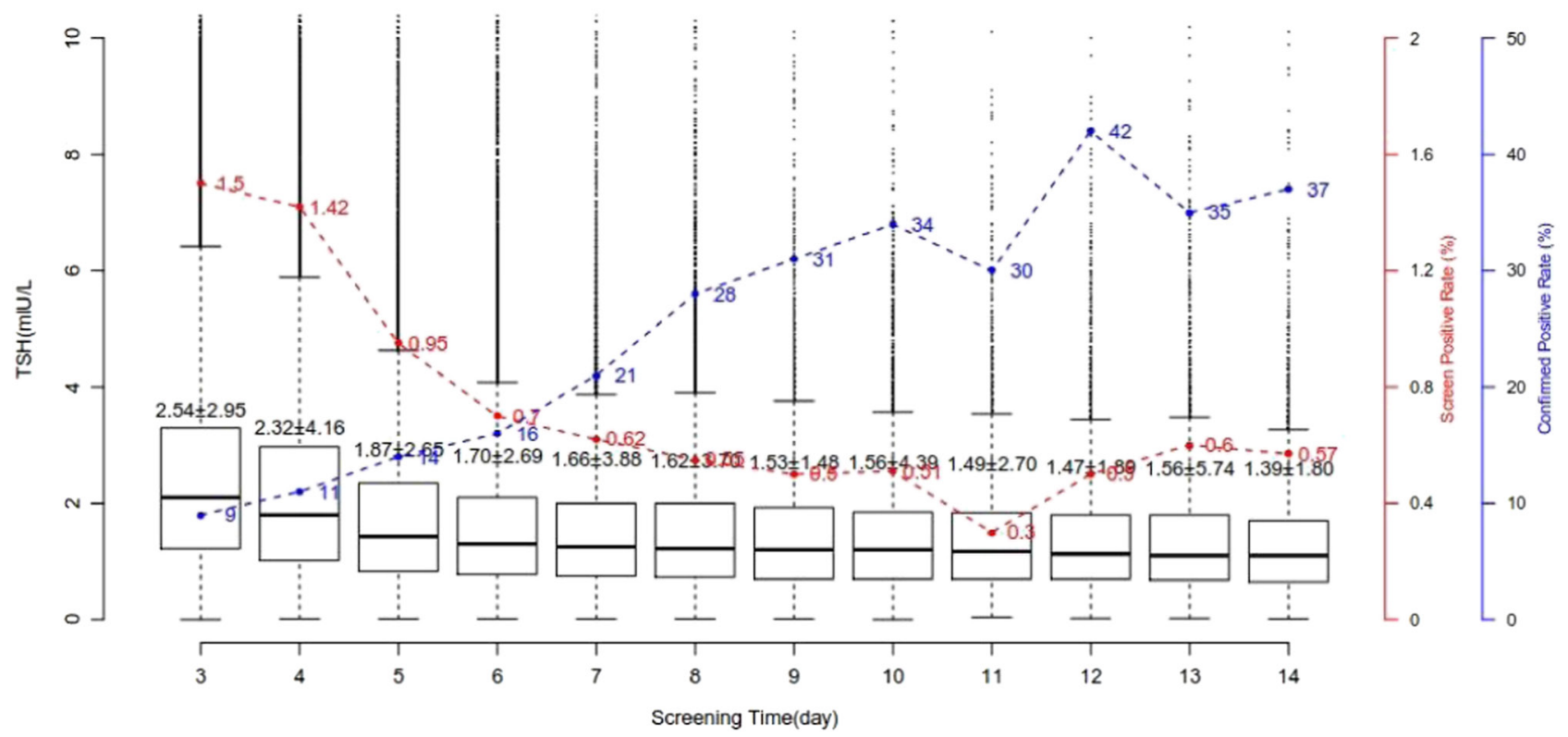

Figure 1

Variation of the TSH levels and positive rate based on the timing of newborn screening sampling.

\begin{tabular}{lr}
\hline http://www.endocrineconnections.org & ○ 2017 The authors \\
DOI: $10.1530 /$ EC-17-0289 & Published by Bioscientifica Ltd
\end{tabular}

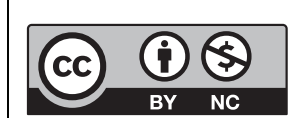

This work is licensed under a Creative Commons Attribution-NonCommercial 4.0 International License. 
A

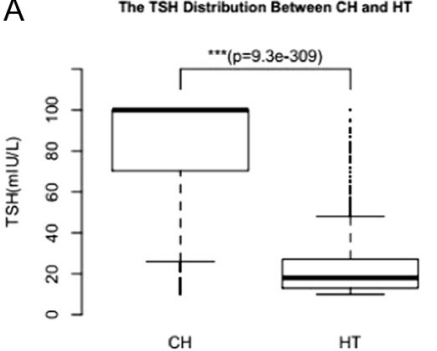

$\mathrm{CH}$
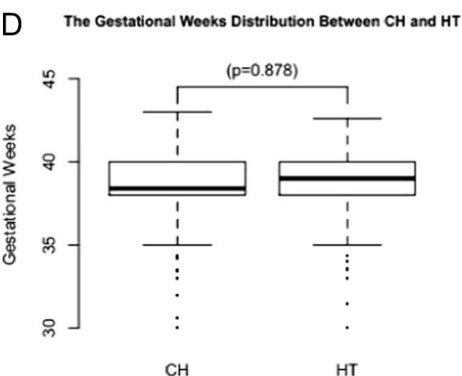

B

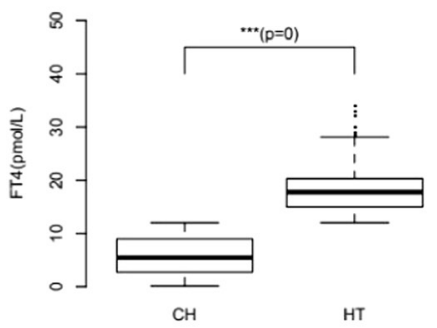

E

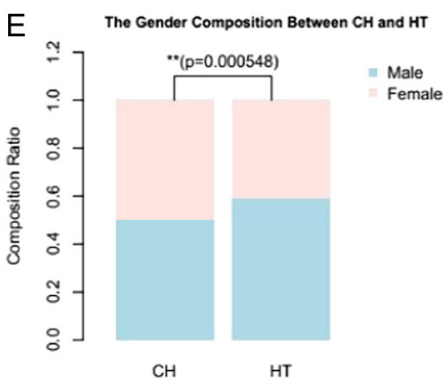

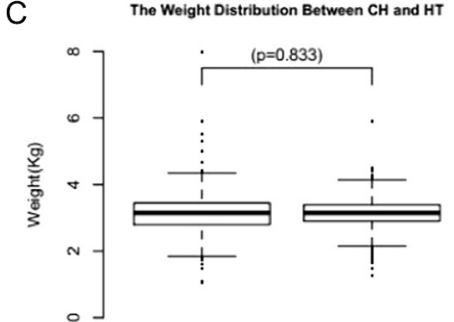

$\mathrm{CH}$

HT

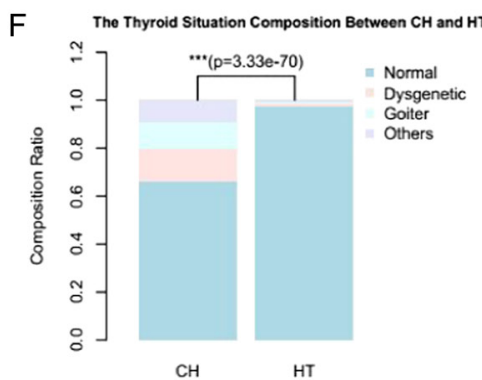

Figure 2

The clinical differences between HT and CH: TSH levels at diagnosis (A), $\mathrm{FT}_{4}$ levels at diagnosis (B), weight (C), gestational weeks (D), gender composition (E) and thyroid morphology (F).

after birth. $97 \%$ of the neonates were screened within the first two weeks after birth. The distribution of serum TSH levels among screened newborns is shown in Table 1. We plotted the mean TSH levels and the positive rates from days 3 to day 14 and observed a concomitant decline of TSH levels and screening positive rates, but a significant improvement in confirmed positive rates (Fig. 1).

The mean TSH level at newborn screening in all measured samples was $2.3 \pm 3.2 \mathrm{IU} / \mathrm{L}$. The mean birth weight was $3113.1 \pm 438.9 \mathrm{~g}$ and the mean gestation was $38.8 \pm 1.6$ weeks. Overall, 14,443 neonates $(1.18 \%)$ were detected to have high TSH levels in the first and second dry samples and were recalled for confirmatory test. The confirmatory test revealed normal $\mathrm{FT}_{4}$ levels and elevation of TSH in 911 neonates. These newborns were diagnosed as HT. 731 were diagnosed as $\mathrm{CH}$ with elevation of TSH levels and decreased $\mathrm{FT}_{4}$ levels. The incidence of $\mathrm{CH}$ and hyperthyrotropinemia was 1/1694 and 1/1359, respectively. The significant differences between HT and $\mathrm{CH}$ regarding $\mathrm{TSH}$ (Fig. $2 \mathrm{~A}$ ) and $\mathrm{FT}_{4}$ levels at diagnosis (Fig. 2B) are expected based on the definition. The analysis also revealed that more females are diagnosed with $\mathrm{CH}$ and more males are diagnosed with HT (Fig. 2E). Compared with individuals with HT, significantly more individuals with $\mathrm{CH}$ had abnormal thyroid morphology (Fig. 2F). There were no statistical differences between $\mathrm{HT}$ and $\mathrm{CH}$ regarding weight (Fig. 2C) and gestational weeks (Fig. 2D).
Among neonates with $\mathrm{CH}, 360$ (49.2) were male and 371 (50.8) were female (female:male ratio 1.03:1). The prevalence of $\mathrm{CH}$ among male and female neonates was $1: 1855$ and 1:1538, respectively, and the difference was statistically significant $(P=0.012)$. The mean TSH level at diagnosis of $\mathrm{CH}$ neonates was $83.51 \pm 26.84 \mathrm{IU} / \mathrm{L}$. The mean birth weight of $\mathrm{CH}$ neonates was $3158.6 \pm 775.6 \mathrm{~g}$ and the mean gestation was $38.9 \pm 1.6$ weeks. The birth weight and gestation weeks are not different in $\mathrm{CH}$ neonates in comparison to non-CH neonates. 57,981 of all newborns and 52 of the $731 \mathrm{CH}$ cases were pre-term babies, and 10,509 of all newborns and 12 of the $731 \mathrm{CH}$ had low birth weight. The $\mathrm{CH}$ prevalence are significantly higher among pre-term $(P<0.002)$ and small for gestational age newborns $(P<0.019)$ compared with full-term newborns and norm birth weight newborns.

Of the 731 patients with $\mathrm{CH}, 161$ patients were diagnosed as $\mathrm{PCH}$ and 159 patients were diagnosed as $\mathrm{TCH}$, the PCH-to-TCH rate was about $1: 1$. The other 411 patients are too young to withdraw $\mathrm{L}_{-} \mathrm{T}_{4}$ therapy, so we cannot determine their clinical phenotype. There were statistical differences between $\mathrm{PCH}$ and $\mathrm{TCH}$ regarding TSH levels at diagnosis (Fig. 3A), $\mathrm{FT}_{4}$ levels at diagnosis (Fig. 3B) and thyroid morphology composition (Fig. 3F). There were no statistical differences between $\mathrm{PCH}$ and $\mathrm{TCH}$ regarding gestation weeks (Fig. 3D), weight (Fig. 3C) and gender composition (Fig. 3E). http://www.endocrineconnections.org DOI: 10.1530/EC-17-0289
C 2017 The authors Published by Bioscientifica Ltd
This work is licensed under a Creative Commons Attribution-NonCommercial 4.0 International License. 
A

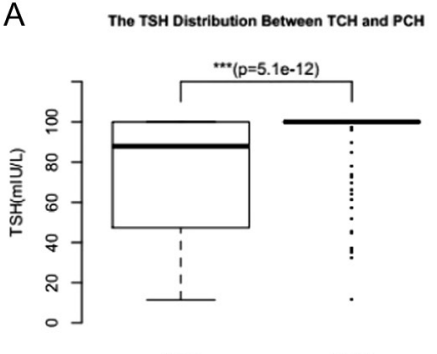

$\mathrm{TCH}$

D

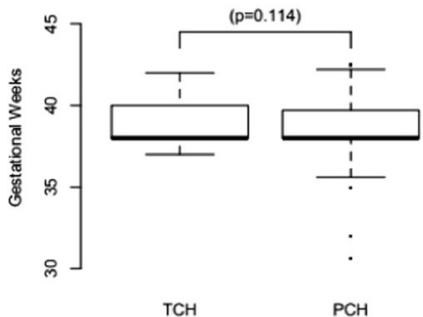

B

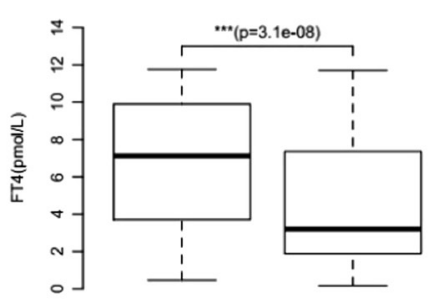

$\mathrm{PCH}$

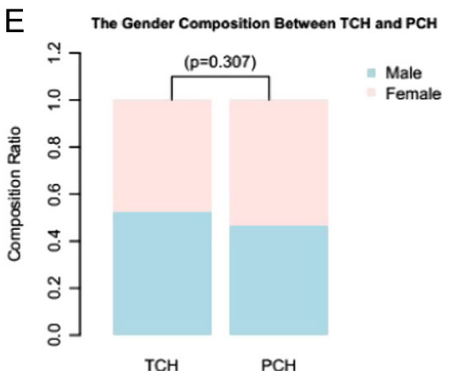

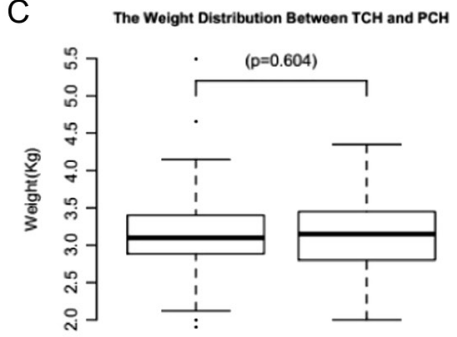

TCH

$\mathrm{PCH}$

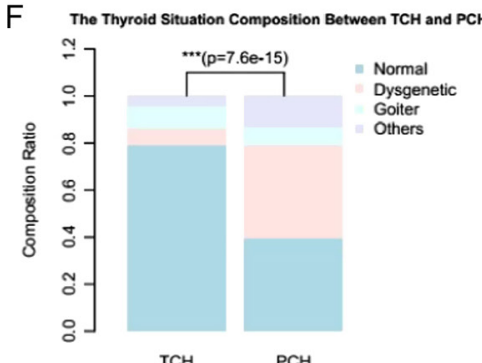

Figure 3

The clinical differences between TCH and PCH: TSH levels at diagnosis (A), $\mathrm{FT}_{4}$ levels at diagnosis (B), weight (C), gestational weeks (D), gender composition (E) and thyroid morphology (F).

The individual doses and average dose of $\mathrm{L}_{-} \mathrm{T}_{4}$ at different age of newborns with $\mathrm{PCH}$ and $\mathrm{TCH}$ were shown in Fig. 4A and B, respectively. It is obvious that the $\mathrm{PCH}$ patients require a higher dosage and longer treatment duration. At the age of 900 days, $29.6 \%$ of TCH patients were treated with an average ${\mathrm{L}-\mathrm{T}_{4}}_{4}$ dose of $7.8 \mu \mathrm{g} / \mathrm{day}$, whereas $100 \%$ of $\mathrm{PCH}$ patients were treated with an average dose of $38.9 \mu \mathrm{g} /$ day.

The dependence on $\mathrm{L}-\mathrm{T}_{4}$ showed a significant difference between $\mathrm{PCH}$ and $\mathrm{TCH}$. To further evaluate the effectiveness of using $\mathrm{L}-\mathrm{T}_{4}$ as a predictor, we performed ROC curve analysis at different times after diagnosis. The differentiating power increases at a later time point (Fig. 5A). The $\mathrm{L}-\mathrm{T}_{4}$ doses used at 90 days is a relatively better predictor taking into account of early diagnosis, the area under the curve (AUC), sensitivity and specificity (Supplementary Table 2).

We also evaluated the effectiveness for differentiating $\mathrm{PCH}$ and TCH using TSH levels at diagnosis, $\mathrm{FT}_{4}$ levels at diagnosis and $\mathrm{L}^{-\mathrm{T}_{4}}$ doses at 90 days (Fig. 5B). Based on the ROC curve analysis, we determined the optimal cutoff values for predicting $\mathrm{CH}$ subtypes: The TSH levels at diagnosis was set at $97.1 \mathrm{IU} / \mathrm{L}$, which yielded a sensitivity of $84.56 \%$ and a specificity of $52.94 \%$, with the AUC at 0.6889 ; the $\mathrm{L}-\mathrm{T}_{4}$ doses at 90 days was set at $30 \mu \mathrm{g} / \mathrm{day}$, which yielded a sensitivity of $58.09 \%$ and a specificity of $78.68 \%$, with the AUC at 0.7220 and the value of $\mathrm{FT}_{4}$ levels at diagnosis was set at $4.6 \mathrm{pmol} / \mathrm{L}$, which yielded a
() 2017 The authors Published by Bioscientifica Ltd sensitivity of $60.29 \%$ and a specificity of $69.85 \%$, with the AUC at 0.6690 .

To further assess the accuracy of the cutoffs for differentiating $\mathrm{PCH}$ and $\mathrm{TCH}$ determined by retrospective patient cohort, we used 33 prospective patients subsequently (Supplementary Table 3), who were identified with $\mathrm{PCH}$ or $\mathrm{TCH}$ from the total $731 \mathrm{CH}$ cases during the process of manuscript preparation. As a result, the accuracy of predicting the $\mathrm{CH}$ subtypes are 60.6, 66.7 and $93.9 \%$ using the cutoff values of TSH levels at diagnosis, $\mathrm{FT}_{4}$ levels at diagnosis and $\mathrm{L}-\mathrm{T}_{4}$ doses at 90 days respectively. The $\mathrm{L}-\mathrm{T}_{4}$ doses at 90 days is the best predictor of high accuracy.

\section{Discussion}

In this study, over 1.2 million newborns from Guangxi Zhuang Autonomous Region, China were screened for $\mathrm{CH}$ using a standard procedure with $8 \mathrm{IU} / \mathrm{L}$ as a cutoff value for TSH. As a result, $1.18 \%$ neonates were recalled for confirmatory test. This re-rate is higher than that of Mexico (0.15\%) (9), Brazil (0.21\%) (10), Netherlands $(0.18 \%)(11)$ and Thailand $(0.24 \%)(12)$, but lower than that of Iran (1.76\%) (13), Turkey (7.2\%) (14), India (1.39\%) (15) and Bahrain (4\%) (16).

The confirmed $\mathrm{CH}$ incidence is $1 / 1694$ in this population. It is known that the incidence of $\mathrm{CH}$ could http://www.endocrineconnections.org DOI: 10.1530/EC-17-0289 
A The Dose Between TCH and PCH

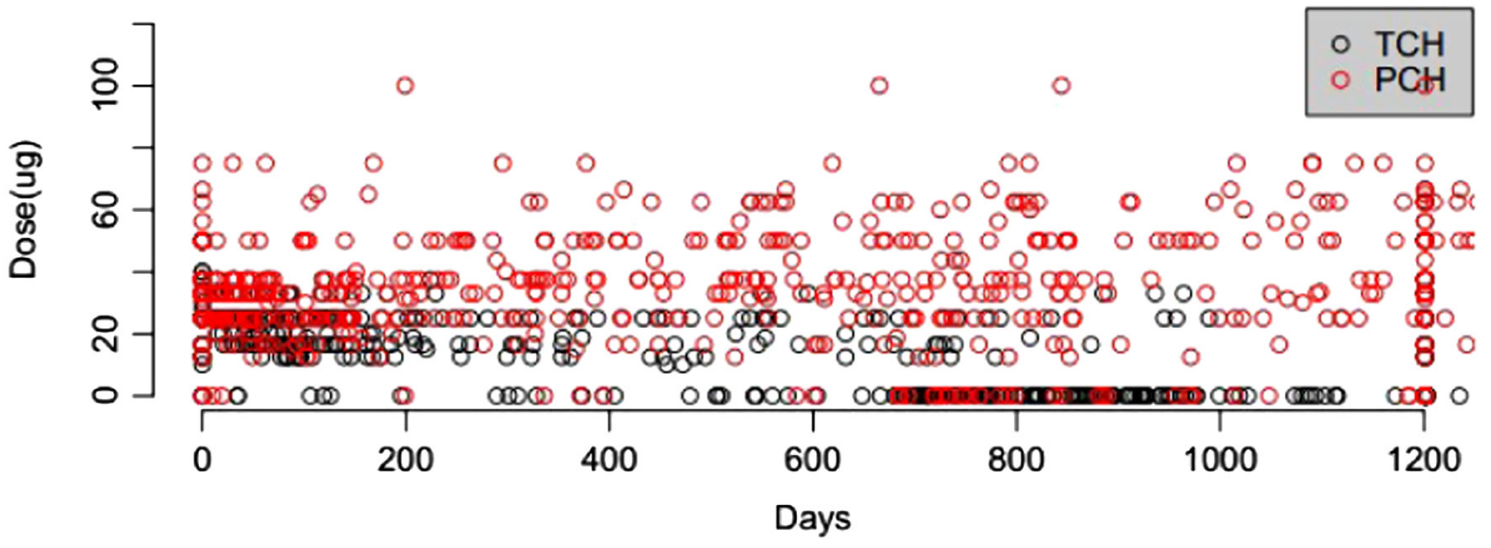

B

The Mean Dose Between TCH and PCH

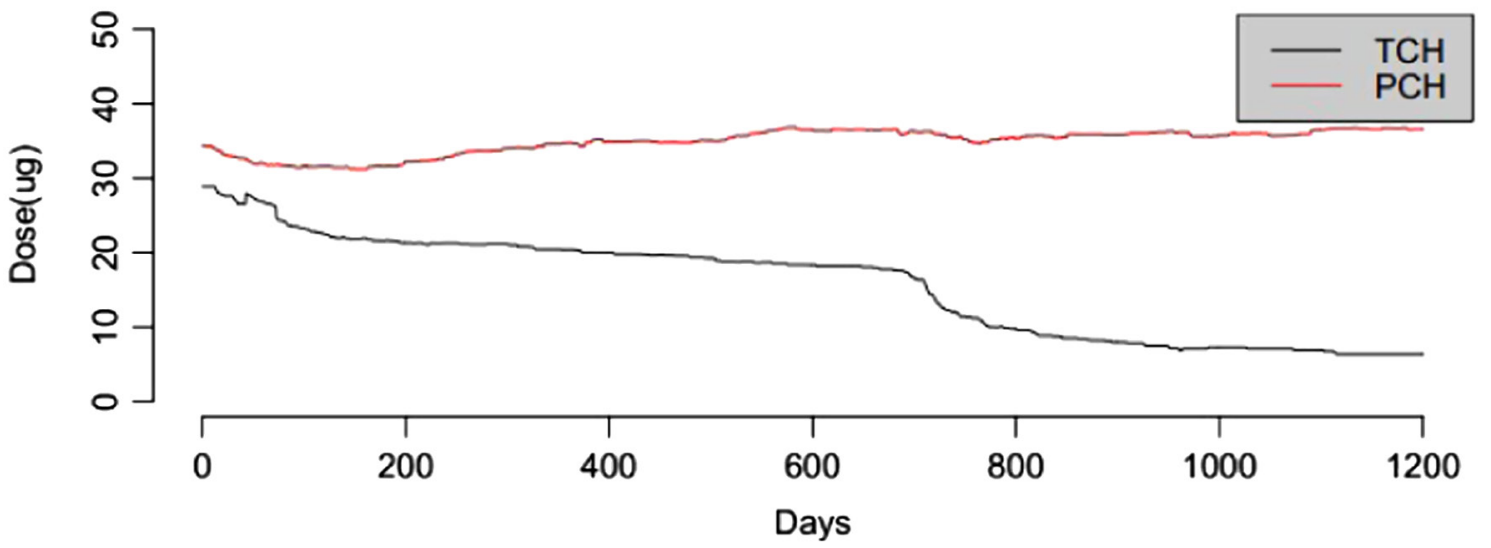

Figure 4

The doses of $\mathrm{L}_{4} \mathrm{~T}_{4}$ used for $\mathrm{CH}$ patients at different age (black line for $\mathrm{TCH}$ and red line for $\mathrm{PCH}$ ).

vary significantly from one ethnic group to another $(1 / 370$ (17) to 1/10,000 (18)). Currently, the overall incidence of $\mathrm{CH}$ in Chinese population is not known, two previous studies based on populations in Zhejiang and Shanghai provided the incidences for Han Chinese as 1:1678 and 1:3009, respectively. Guangxi Zhuang Autonomous Region is dominated with Zhuang minority, a distinct ethnic group from Han. Our study revealed that the incidence of $\mathrm{CH}$ among newborns in Guangxi Zhuang Autonomous Region is similar to that of Han Chinese in Zhejiang (6) and slightly higher than the average worldwide incidence $(1 / 2000-1 / 4000)(1,2,3)$.

We have used a relative low cutoff value of TSH in this newborn screening program. 97\% of the screening test was done within 3-14 days of life. For the first time, we plotted the mean TSH levels in the newborns period based on a large cohort of population and noticed a rapid decrease of TSH level in the first several days (Fig. 1). Noticeably, the positive screening rates also showed a similar decline. More importantly, the confirmed positive rates or false-positive rate also correlated with the average level of TSH at different days after birth. This finding challenged the validity of using one cutoff value of TSH for newborn $\mathrm{CH}$ screening at any days after birth. Further study can help to determine the right cutoff value for samples collected at different days after birth.

Recent studies suggest that the TSH levels, weight, gender, $\mathrm{FT}_{4}$ levels, gestational weeks and the thyroid morphology may correlate with the etiology of $\mathrm{CH}(19,20$, 21). In our study, there were statistical differences between HT and $\mathrm{CH}$ regarding TSH levels, gender composition, $\mathrm{FT}_{4}$ levels and thyroid morphology composition. There were also statistical differences between $\mathrm{PCH}$ and $\mathrm{TCH}$ regarding the $\mathrm{TSH}$ levels, $\mathrm{FT}_{4}$ levels and the thyroid morphology, but no significant differences in gestation weeks, gender and weight were found between the two groups. It demonstrated the correlation between the three http://www.endocrineconnections.org DOI: 10.1530/EC-17-0289 (c) 2017 The authors Published by Bioscientifica Ltd

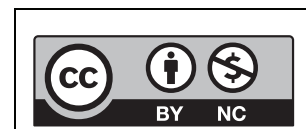

This work is licensed under a Creative Commons Attribution-NonCommercial 4.0 International License. 
A

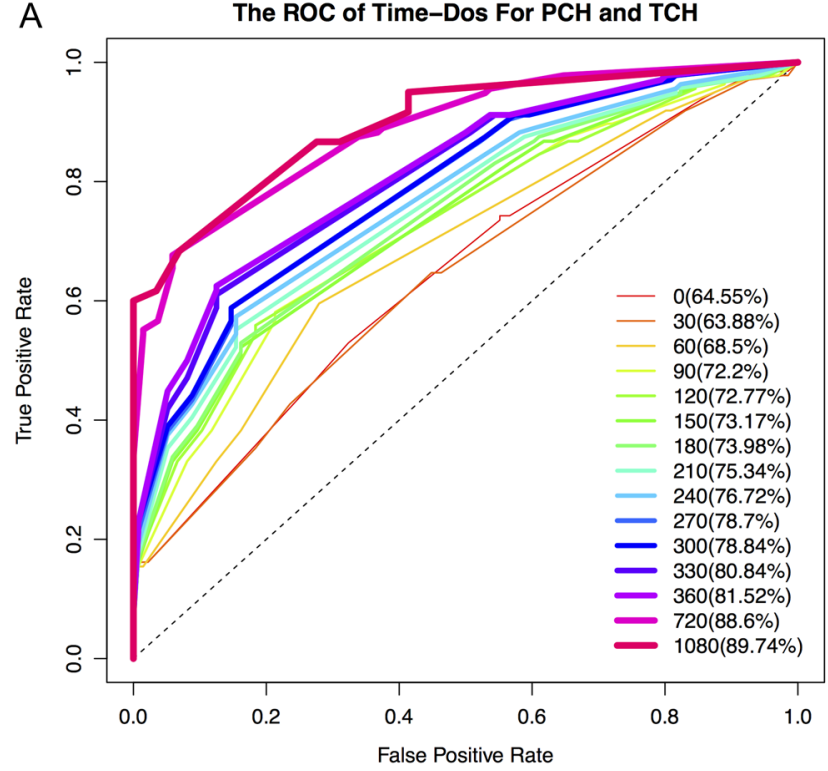

B

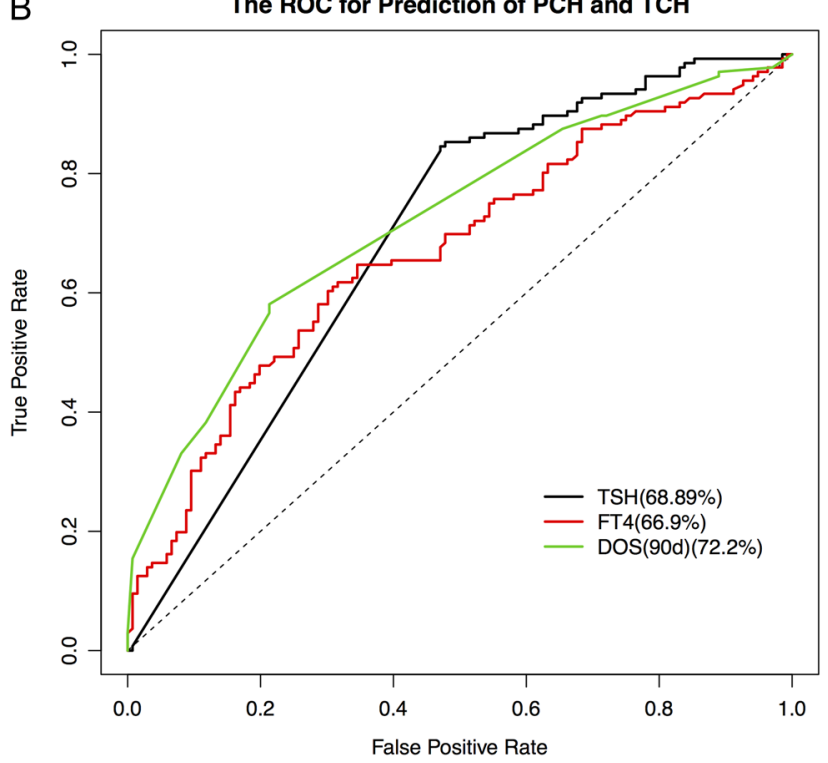

Figure $\mathbf{5}$

(A) The ROC curve L-T 4 doses at different time after diagnosis; (B) the ROC curve of TSH levels at diagnosis, $\mathrm{L}_{4} \mathrm{~T}_{4}$ doses 90 days after diagnosis and $\mathrm{FT} 4$ levels for predicting $\mathrm{PCH}$ and $\mathrm{TCH}$.

factors (TSH levels, $\mathrm{FT}_{4}$ levels and thyroid morphology) and hypothyroidism.

Nearly all screening programs report a female preponderance among $\mathrm{CH}$ patients, often approaching a 2:1 female-to-male ratio $(1,5)$. In our study, this ratio was 1.03:1. The difference may be caused by the population gender bias among screened newborns (male:female 1.17) and etiological diversity of $\mathrm{CH}$ in different ethnic groups.

The PCH-to-TCH rate in our $\mathrm{CH}$ patients is bout 1:1. It is similar to that recently reported by other authors, who found rates ranging from 38 to $46 \%(19,21,22)$. Therefore, according to our and other authors' results, more than one-third of the infants diagnosed with $\mathrm{CH}$ by neonatal screening will not require lifelong $\mathrm{L}_{-} \mathrm{T}_{4}$ therapy, and reliable markers that would allow earlier detection of TCH might be useful.

Treatment plan and prognosis differ significantly for patients with PCH or TCH. Often, it is not known what $\mathrm{CH}$ subtype each newborn-screen-positive patient has until L- $\mathrm{T}_{4}$ withdrawal at approximately $2-3$ years of age. It is beneficial to have an earlier differentiation. In the past few years, several studies $(19,20,21,23,24,25,26,27,28$, 29) tried to identify the factors that could allow an early discrimination between the cases with either P or $\mathrm{T} \mathrm{CH}$. In a study conducted by Unuvar and coworkers (19), T4 dose required to maintain a euthyroid state was the parameter that distinguished between TCH and PCH. Rabbiosi and coworkers (21), in a study conducted in Italy, reported major risk factors for $\mathrm{PCH}$ were prematurity, thyroid hypoplasia at diagnosis, first-degree familial history of goiter/nodules and high L- $\mathrm{T}_{4}$ requirements at follow-up. Hashemipour and coworkers, in a study conducted in Iran, reported $\mathrm{PCH}$ was associated with higher initial TSH and T4 levels than TCH. Skordis and coworkers (27) stated that $\mathrm{L}_{-} \mathrm{T}_{4}$ requirements $>4.9 \mu \mathrm{g} / \mathrm{kg} /$ day at 12 months or $>4.27 \mu \mathrm{g} / \mathrm{kg} /$ day at 24 months are highly suggestive of $\mathrm{PCH} ; \mathrm{L}_{-} \mathrm{T}_{4}$ requirements $<1.7 \mu \mathrm{g} / \mathrm{kg} /$ day at 12 months or $<1.45 \mu \mathrm{g} / \mathrm{kg} /$ day at 24 months are highly suggestive of $\mathrm{TCH}$. Messina and coworkers (20) reported the initial measurements of the serum TSH level and the required doses of $\mathrm{L}-\mathrm{T}_{4}$ therapy for maintaining normal thyroid hormone levels, growth and development may have a predictive role for differentiating $\mathrm{PCH}$ from $\mathrm{TCH}$.

So far, although a few studies have been conducted with the purpose of determining how best to discriminate between cases with either $\mathrm{TCH}$ or $\mathrm{PCH}$ before the age of 3 years, the evolution of $\mathrm{CH}$ remains difficult to predict, mainly due to the lack of large-scale, long-term and in-depth studies. In our study, we evaluated the effectiveness using L- $\mathrm{T}_{4}$ dose, as well as TSH and $\mathrm{FT}_{4}$ levels at diagnosis as predictors for an early differentiation using so far the largest cohort of patients. Using multiple statistical methods, we found that children with a higher initial $\mathrm{L}_{-} \mathrm{T}_{4}$ dose and requiring increasing doses of $\mathrm{L}_{4} \mathrm{~T}_{4}$ during the first few years of treatment are likely to have $\mathrm{PCH}$. Conversely, patients with a lower initial $\mathrm{L}_{-} \mathrm{T}_{4}$ dose http://www.endocrineconnections.org DOI: 10.1530/EC-17-0289 (c) 2017 The authors Published by Bioscientifica Ltd
This work is licensed under a Creative Commons Attribution-NonCommercial 4.0 International License. 
and requiring decreasing doses are likely to have TCH. High TSH levels and low $\mathrm{FT}_{4}$ levels at diagnosis were found to be significant predictors for PCH. The $\mathrm{L}_{-} \mathrm{T}_{4}$ doses, however, are the best independent predictor. An $\mathrm{L}_{-} \mathrm{T}_{4}$ dose requirement at 90 days $>30 \mu \mathrm{g}$ /day demonstrated an accuracy of $93.9 \%$ for our prospective cohort.

In conclusion, the incidence of $\mathrm{CH}$ and hyperthyrotropinemia among newborns in Guangxi Zhuang Autonomous Region, China was 1/1694 and $1 / 1359$, respectively. The permanent $\mathrm{CH}$ and transient $\mathrm{CH}$ ratio is close to 1 ; thus, the estimated $\mathrm{PCH}$ incidence is $1 / 3708$. There were statistical differences between hyperthyrotropinemia and $\mathrm{CH}$ regarding TSH levels, sex, $\mathrm{FT}_{4}$ levels and thyroid morphology; there were also statistical differences between $\mathrm{PCH}$ and $\mathrm{TCH}$ regarding the same four factors. Children with $\mathrm{CH}$ requiring increasing $\mathrm{L}_{-} \mathrm{T}_{4}$ doses during the first years of treatment are at risk for $\mathrm{PCH}$; children with $\mathrm{CH}$ demonstrating decreased $\mathrm{L}_{-} \mathrm{T}_{4}$ dependency to maintain normal TSH values over time are likely to have TCH. An $\mathrm{L}-\mathrm{T}_{4}$ dose requirement at 90 days $>30 \mu \mathrm{g} /$ day is highly suggestive of $\mathrm{PCH}$.

\section{Supplementary data}

This is linked to the online version of the paper at http://dx.doi.org/10.1530/ EC-17-0289.

\section{Declaration of interest}

The authors declare that there is no conflict of interest that could be perceived as prejudicing the impartiality of the research reported.

\section{Funding}

This study was supported by the National Natural Science Foundation of China (81260126), Key Projects of Guangxi Health Department (2012025) and Guangxi Natural Science Foundation Program (2016GXNSFBA380192, 2012GXNSFAA053174).

\section{References}

1 Rastogi MV \& LaFranchi SH. Congenital hypothyroidism. Orphanet Journal of Rare Diseases 20105 17. (doi:10.1186/1750-1172-5-17)

2 Hermanns P, Grasberger H, Cohen R, Freiberg C, Dorr HG, Refetoff S $\&$ Pohlenz J. Two cases of thyroid dysgenesis caused by different novel PAX8 mutations in the DNA-binding region: in vitro studies reveal different pathogenic mechanisms. Thyroid 201323 791-796. (doi:10.1089/thy.2012.0141)

3 Liu SG, Zhang SS, Zhang LQ, Li WJ, Zhang AQ, Lu KN, Wang MJ, Yan SL \& Ma X. Screening of PAX8 mutations in Chinese patients with congenital hypothyroidism. Journal of Endocrinological Investigation 201235 889-892. (doi:10.3275/8239)

4 Zeinalzadeh AH \& Talebi M. Neonatal screening for congenital hypothyroidism in East Azerbaijan, Iran: the first report. Journal of Medical Screening 201219 123-126. (doi:10.1258/jms.2012.012024)
5 Kocova M, Anastasovska V, Sukarova-Angelovska E, Tanaskoska M \& Taseva E. Clinical practice: experience with newborn screening for congenital hypothyroidism in the Republic of Macedonia - a multiethnic country. European Journal of Pediatrics 2015174 443-448. (doi:10.1007/s00431-014-2413-4)

6 Maitusong R, Japaer R, Zhao ZY, Yang RL, Huang XL \& Mao HQ. Newborn screening in Zhejiang, China. Chinese Medical Journal 2012 125 702-704.

7 Gu XF \& Wang ZG. Screening for phenylketonuria and congenital hypothyroidism in 5.8 million neonates in China. Zhonghua Yu Fang Yi Xue Za Zhi 200438 99-102. (doi:10.3760/ j:issn:0253-9624.2004.02.009)

8 Leger J, Olivieri A, Donaldson M, Torresani T, Krude H, van Vliet G, Polak M, Butler G, Espe Pes Slep Jspe Apeg Appes I \& Congenital Hypothyroidism Consensus Conference G. European Society for Paediatric Endocrinology consensus guidelines on screening, diagnosis, and management of congenital hypothyroidism. Journal of Clinical Endocrinology and Metabolism 201499 363-384. (doi:10.1210/ jc.2013-1891)

9 Rendon-Macias ME, Morales-Garcia I, Huerta-Hernandez E, SilvaBatalla A \& Villasis-Keever MA. Birth prevalence of congenital hypothyroidism in Mexico. Paediatric and Perinatal Epidemiology 2008 22 478-485. (doi:10.1111/j.1365-3016.2008.00955.x)

10 Ramalho AR, Ramalho RJ, Oliveira CR, Santos EG, Oliveira MC \& Aguiar-Oliveira MH. Neonatal screening program for congenital hypothyroidism in northeast of Brazil: criteria, diagnosis and results. Arquivos Brasileiros de Endocrinologia e Metabologia 200852 617-627. (doi:10.1590/S0004-27302008000400007)

11 Kempers MJ, Lanting CI, van Heijst AF, van Trotsenburg AS, Wiedijk BM, de Vijlder JJ \& Vulsma T. Neonatal screening for congenital hypothyroidism based on thyroxine, thyrotropin, and thyroxine-binding globulin measurement: potentials and pitfalls. Journal of Clinical Endocrinology and Metabolism 200691 3370-3376. (doi:10.1210/jc.2006-0058)

12 Charoensiriwatana W, Janejai N, Boonwanich W, Krasao P, Chaisomchit S \& Waiyasilp S. Neonatal screening program in Thailand. Southeast Asian Journal of Tropical Medicine and Public Health 200334 (Supplement 3) 94-100.

13 Baf MM, Baf MM, Noorollahi F, Baf MM, Bandarian F \& Sara Y. Neonatal screening for congenital hypothyroidism in Razavi Khorasan Province, Iran. Journal of Clinical Research in Pediatric Endocrinology 20168 352-356. (doi:10.4274/jcrpe.3425)

14 Caylan N, Tezel B, Ozbas S, Sahin N, Aydin S, Acican D \& Keskinkilic B. Neonatal thyroid-stimulating hormone screening as a monitoring tool for iodine deficiency in Turkey. Journal of Clinical Research in Pediatric Endocrinology 20168 187-191. (doi:10.4274/jcrpe.2526)

15 Gopalakrishnan V, Joshi K, Phadke S, Dabadghao P, Agarwal M, Das V, Jain S, Gambhir S, Gupta B, Pandey A, et al. Newborn screening for congenital hypothyroidism, galactosemia and biotinidase deficiency in Uttar Pradesh, India. Indian Pediatrics 2014 51 701-705. (doi:10.1007/s13312-014-0485-x)

16 Golbahar J, Al-Khayyat H, Hassan B, Agab W, Hassan E \& Darwish A. Neonatal screening for congenital hypothyroidism: a retrospective hospital based study from Bahrain. Journal of Pediatric Endocrinology and Metabolism 201023 39-44.

17 Hashemipour M, Hovsepian S \& Kelishadi R. High prevalence of congenital hypothyroidism in Isfahan: do familial components have a role? Advanced Biomedical Research 20121 37. (doi:10.4103/22779175.100130)

18 Roberts HE, Moore CA, Fernhoff PM, Brown AL \& Khoury MJ. Population study of congenital hypothyroidism and associated birth defects, Atlanta, 1979-1992. American Journal of Medical Genetics 1997 71 29-32. (doi:10.1002/(SICI)1096-8628(19970711)71:1<29::AIDAJMG5>3.0.CO;2-L)

19 Unuvar T, Demir K, Abaci A, Buyukgebiz A \& Bober E. The role of initial clinical and laboratory findings in infants with

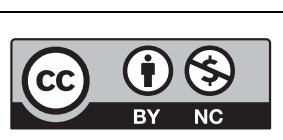

This work is licensed under a Creative Commons Attribution-NonCommercial 4.0 International License. 
hyperthyrotropinemia to predict transient or permanent hypothyroidism. Journal of Clinical Research in Pediatric Endocrinology 20135 170-173. (doi:10.4274/Jcrpe.931)

20 Messina MF, Aversa T, Salzano G, Zirilli G, Sferlazzas C, De Luca F \& Lombardo F. Early discrimination between transient and permanent congenital hypothyroidism in children with eutopic gland. Hormone Research in Paediatrics 201584 159-164. (doi:10.1159/000435811)

21 Rabbiosi S, Vigone MC, Cortinovis F, Zamproni I, Fugazzola L, Persani L, Corbetta C, Chiumello G \& Weber G. Congenital hypothyroidism with eutopic thyroid gland: analysis of clinical and biochemical features at diagnosis and after re-evaluation. Journal of Clinical Endocrinology and Metabolism 201398 1395-1402. (doi:10.1210/jc.2012-3174)

22 Cho MS, Cho GS, Park SH, Jung MH, Suh BK \& Koh DG. Earlier re-evaluation may be possible in pediatric patients with eutopic congenital hypothyroidism requiring lower L-thyroxine doses. Annals of Pediatric Endocrinology and Metabolism 201419 141-145. (doi:10.6065/apem.2014.19.3.141)

23 Zung A, Tenenbaum-Rakover Y, Barkan S, Hanukoglu A, Hershkovitz E, Pinhas-Hamiel O, Bistritzer T \& Zadik Z. Neonatal hyperthyrotropinemia: population characteristics, diagnosis, management and outcome after cessation of therapy. Clinical Endocrinology 201072 264-271. (doi:10.1111/j.13652265.2009.03634.x)
24 Ghasemi M, Hashemipour M, Hovsepian S, Heiydari K, Sajadi A, Hadian R, Mansourian M, Mirshahzadeh N \& Dalvi M. Prevalence of transient congenital hypothyroidism in central part of Iran. Journal of Research in Medical Sciences 201318 699-703.

25 Langham S, Hindmarsh P, Krywawych S \& Peters C. Screening for congenital hypothyroidism: comparison of borderline screening cut-off points and the effect on the number of children treated with levothyroxine. European Thyroid Journal 20132 180-186. (doi:10.1159/000350039)

26 Hashemipour M, Hovsepian S, Kelishadi R, Iranpour R, Hadian R, Haghighi S, Gharapetian A, Talaei M \& Amini M. Permanent and transient congenital hypothyroidism in Isfahan-Iran. Journal of Medical Screening 2009 16 11-16. (doi:10.1258/jms.2009.008090)

27 Skordis N, Toumba M, Savva SC, Erakleous E, Topouzi M, Vogazianos M \& Argyriou A. High prevalence of congenital hypothyroidism in the Greek Cypriot population: results of the neonatal screening program 1990-2000. Journal of Pediatric Endocrinology and Metabolism 200518 453-461.

28 Eugster EA, LeMay D, Zerin JM \& Pescovitz OH. Definitive diagnosis in children with congenital hypothyroidism. Journal of Pediatrics 2004144 643-647. (doi:10.1016/j.jpeds.2004.02.020)

29 Kara C, Günindi F, Can Yılmaz G \& Aydın M. Transient congenital hypothyroidism in Turkey: an analysis on frequency and natural course. Journal of Clinical Research in Pediatric Endocrinology 20168 170-179. (doi:10.4274/jcrpe.2345)

Received in final form 23 October 2017

Accepted 26 October 2017

Accepted preprint published online 26 October 2017 http://www.endocrineconnections.org DOI: 10.1530/EC-17-0289
(C) 2017 The authors Published by Bioscientifica Ltd

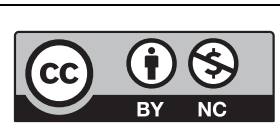

This work is licensed under a Creative Commons Attribution-NonCommercial 4.0 International License. 